\title{
INVESTIGACIONES
}

\section{Un estudio comparativo de los deberes escolares en el alumnado extranjero y no extranjero*}

\author{
A comparative study of homework \\ in the foreign and non-foreign students
}

\author{
Antonio Valle ${ }^{a}$, Paula Rodríguez-Prado ${ }^{a}$, Bibiana Regueiro ${ }^{b}$, \\ Iris Estévez ${ }^{a}$, Isabel Piñeiro ${ }^{a}$, Susana Rodríguez ${ }^{a}$ \\ ${ }^{a}$ Universidade da Coruña, Facultad de Ciencias de la Educación, España. \\ vallar@udc.es, paularodriguezprado@gmail.com, iris.estevezb@udc.es, ipineiro@udc.es, susana@udc.es \\ ${ }^{b}$ Universidade de Santiago de Compostela. Facultad de Ciencias de la Educación, España. \\ bibiana.regueiro@usc.es
}

\begin{abstract}
Los deberes escolares han despertado un gran interés tanto en el plano académico como social en las últimas décadas. Sin embargo, los estudios realizados con población extranjera sobre los deberes escolares todavía son muy escasos y los que existen aportan datos muy generales. El propósito de este trabajo es realizar un análisis comparativo entre el alumnado extranjero y no extranjero con respecto a diversas variables vinculadas con los deberes escolares. Paralelamente, se estudia si hay diferencias entre ambos grupos en función de la etapa educativa. La muestra está integrada por 94 estudiantes de edades comprendidas entre los 9 y los 16 años. Los resultados indican que el grupo de estudiantes no extranjeros realiza una mayor cantidad de deberes (de los prescritos por el profesorado) y percibe un menor control parental que el grupo de estudiantes extranjeros. En cuanto a la etapa educativa, los estudiantes de Primaria realizan una mayor cantidad de deberes, aprovechan más el tiempo, están más motivados intrínsecamente, utilizan más un enfoque de trabajo profundo, perciben un mayor feedback por parte de sus profesores y perciben un mayor control parental cuando hacen los deberes que los estudiantes de Secundaria.
\end{abstract}

Palabras claves: proceso de realización de los deberes escolares, alumnado extranjero, Educación Primaria, Educación Secundaria.

\section{ABSTRACT}

The aim of this study is to perform a comparative analysis between the foreign and non-foreign students with respect to several variables related to homework. Simultaneously, it is studied whether there are differences between the two groups depending on the educational stage. The sample consists of 94 students between the ages of 9 and 16 years. The results indicate that the group of non-foreign students do more homework and perceives less parental control than the group of foreign students. As for the educational stage, primary students do a greater amount of homework, take more time, are more intrinsically motivated, use a deep approach to homework, perceive more feedback from their teachers and perceive greater parental control when they do homework as high school students.

Key words: homework process, foreign students, primary education, secondary education.

\footnotetext{
* Este trabajo se ha desarrollado gracias a la financiación de los proyectos de investigación EDU2013-44062-P (MINECO) y
} EDU2017-82984-P (MEIC). 


\section{INTRODUCCIÓN}

Los deberes escolares (o tareas para casa) se pueden contemplar como un conjunto de trabajos o tareas escolares que prescriben los profesores para ser realizadas por el alumnado fuera del horario lectivo (Cooper, Robinson y Patall, 2006). El elemento que los define es el momento temporal en el que se realizan, no el lugar. Sin embargo, su principal característica quizá sea que se trata de una labor sobre la que el estudiante tiene la responsabilidad principal de los resultados obtenidos, responsabilidad compartida con los padres o tutores en el caso de los más pequeños (Murillo y Martínez-Garrido, 2013).

Ciertamente, la investigación y estudio sobre los deberes ha despertado un gran interés y ha adquirido relevancia tanto en el plano académico como social. Conocer las situaciones, circunstancias y condiciones en las que prescribir los deberes, se presume una cuestión de innegable importancia, pues de ello dependerá que el aprendizaje y el rendimiento académico del alumnado se vea favorecido o, por el contrario, perjudicado. Otro punto importante a tener en cuenta es que los deberes escolares no requieren de un tratamiento único y global para todos los colectivos. Es sabido que actualmente conviven en las aulas alumnos cuyas características personales los convierten en individuos diversos, bien sea por razones de procedencia, cultura, etnia, lengua, religión etc. La diversidad está presente en el contexto educativo y, por tanto, las tareas para casa deben apoyar y entender esta realidad. En este sentido, el alumnado procedente del extranjero constituye un grupo muy relevante que con sus peculiaridades también puede experimentar diferencias respecto al alumnado no extranjero en lo que a los beneficios de los deberes se refiere.

Pese a la abundante investigación que en las últimas décadas se ha generado en torno al tópico de los deberes escolares, la literatura previa no tiene en cuenta ciertas variables importantes como, en este caso, la multiculturalidad de las aulas (Regueiro et al., 2018).

\section{EL PROCESO DE REALIZACIÓN DE LOS DEBERES ESCOLARES}

La investigación en torno al proceso de realización de los deberes escolares ha ido acompañada del desarrollo de diversos modelos que tratan de explicar aquellas variables implicadas en dicho proceso. El más complejo y parsimonioso, pero a la vez el que mejor integra los aspectos más significativos, es el propuesto por Trautwein y Köller (2003). Este modelo se caracteriza por considerar a los estudiantes, padres y profesores como agentes protagonistas en el proceso de realización de los deberes, así como por diferenciar tres bloques de variables. El primero de estos bloques hace referencia al rendimiento académico, incluyendo las calificaciones académicas de los alumnos y su resultado en las pruebas de rendimiento. El segundo aborda la implicación de los estudiantes en los deberes y en este contexto es vital tanto el componente motivacional que incentiva, dirige y mantiene la conducta de trabajo, como el componente cognitivo-conductual, que se identifica con las estrategias cognitivas y metacognitivas utilizadas, el tiempo dedicado, el esfuerzo y la cantidad de deberes realizados. El último bloque se relaciona con la influencia del entorno y en él tienen cabida, tanto la implicación de los padres, como de los docentes en el proceso de realización de los deberes.

De todo ello se mantiene la hipótesis de que en el rendimiento académico de un alumno intervienen de manera interactiva variables personales (motivacionales y de implicación del 
propio estudiante) así como variables contextuales (familiares y escolares). De un modo más amplio, puede decirse que el rendimiento se explica por la magnitud y calidad de la motivación e implicación del alumno en los deberes, y que ese rendimiento también está asociado a la implicación parental y a la implicación de los propios docentes.

\subsection{VARIABLES PERSONALES IMPLICADAS EN LOS DEBERES ESCOLARES}

\subsubsection{Cantidad de deberes escolares realizados}

Actualmente, la gran mayoría de las investigaciones indican que la cantidad de deberes realizados de los que prescribe el profesor se relaciona positivamente con una mejora del rendimiento académico. Así, pues, tan importante es la cantidad de deberes que los docentes prescriben como el porcentaje que los escolares realizan.

Ciertamente, son numerosos los estudios que afirman que los estudiantes que completan sus deberes tienen mejores calificaciones académicas que aquellos que no los terminan. Así, Cooper, Lindsay, Nye y Greathhouse (1998) comprobaron que la cantidad de deberes que los estudiantes realizan correlaciona con su rendimiento académico, tanto en los alumnos de cursos más avanzados como en alumnos de cursos inferiores. Siguiendo la investigación realizada por Pan et al. (2013) existe una relación positiva entre la cantidad de deberes realizados y el rendimiento académico en estudiantes de $4^{\circ}, 5^{\circ}$ y $6^{\circ}$ de Educación Primaria, siendo los alumnos que realizan un mayor número de deberes los que obtienen un rendimiento académico más elevado.

Por su parte, Epstein y Van Voorhis (2001) indican que un mayor número de deberes constituye un argumento de peso para generar un ambiente de aprendizaje adecuado y conseguir el éxito académico. No obstante, lo más revelador es que algunas investigaciones concluyen que, de todas las variables relacionadas con la implicación en los deberes escolares, la cantidad de tareas para casa realizadas por los alumnos parece ser la variable que más predice el rendimiento académico (Valle, Pan, Núñez et al., 2015).

\subsubsection{Tiempo dedicado a los deberes escolares}

Además de la cantidad de deberes, el tiempo que el estudiante dedica para su realización ha sido otra de las variables que más debate ha suscitado, tratando de analizar su influencia sobre el rendimiento académico. En muchas ocasiones permanece latente la idea de que emplear más tiempo en los deberes proporciona a los estudiantes mejores resultados. De hecho, el tiempo utilizado ha sido una variable muy estudiada (Fan, Xu, Cai, He \& Fan, 2017) precisamente porque se suele utilizar la cantidad de tiempo dedicado a los deberes como un indicador del mayor o menor éxito académico.

Siguiendo la investigación llevada a cabo por Keith (1982), un incremento en el tiempo empleado por los alumnos, especialmente en los cursos más elevados, tiene un efecto positivo. Por lo tanto, la relación entre el tiempo dedicado a los deberes y el rendimiento académico debería ser positiva (Fernández-Alonso, Álvarez-Díaz, Suárez-Álvarez \& Muñiz, 2017). Sin embargo, autores como Trautwein (2007) no consideran tan evidente esta relación, sino que más bien la encuentra débil e incluso negativa.

Con todo, aunque algunas investigaciones tienden a mostrar una relación positiva entre el tiempo dedicado a los deberes y el rendimiento académico, más importante que el 
tiempo en sí mismo es el aprovechamiento real del mismo, pues lo que sí resulta evidente es que, a mayor aprovechamiento del tiempo dedicado a los deberes, mayor rendimiento académico.

\subsubsection{Aprovechamiento del tiempo dedicado a los deberes escolares}

En el estudio llevado a cabo por Regueiro et al. (2018) con muestra de estudiantes nativos y extranjeros, los resultados indican que en la variable gestión del tiempo los estudiantes nativos manifiestan un mayor grado de concentración en comparación a los estudiantes extranjeros en la realización de los deberes escolares. Por lo tanto, la clave parece estar en diferenciar entre la calidad y la cantidad de tiempo (Valle et al., 2019), ya que emplear más tiempo en los deberes no conduce necesariamente a un elevado rendimiento. Un alumno puede emplear más tiempo en la realización de los deberes escolares por múltiples motivos, como, por ejemplo cuando presenta dificultades de aprendizaje o cuando su nivel de nivel de conocimientos previos es bajo. Asimismo, la cantidad de tiempo empleado por el estudiante puede estar condicionado por su actitud, por la del docente o mismo por la carga excesiva de deberes, lo que inhibirá al alumno en su realización (Trautwein, 2007).

Por otro lado, el esfuerzo que un alumno invierte para realizar sus deberes escolares no tiene por qué relacionarse directamente con el tiempo que tarda en realizarlos. Así, pues, el esfuerzo dedicado a las tareas para casa, más que el tiempo en sí mismo, ha demostrado tener una incidencia positiva en el rendimiento académico (Regueiro et al., 2014).

Por su parte, Keith (1982) señala que los estudiantes más competentes a nivel académico trabajan con más empeño y eficacia que los menos competentes debido a la estrecha relación entre aprovechamiento y tiempo empleado en los deberes. De ello se deriva que los niveles más altos de rendimiento académico se asocian con un mejor aprovechamiento del tiempo dedicado a los deberes y con un menor gasto de tiempo para realizarlos.

En definitiva, la relación entre la cantidad de deberes realizados, el tiempo dedicado a los mismos y el rendimiento obtenido podría estar influida decisivamente por el aprovechamiento real del tiempo empleado por el alumno. Y en el caso de los alumnos extranjeros particularmente, ya que muchas otras variables pueden afectar a la implicación como el dominio del idioma; la cultura de procedencia (Mau \& Lynn, 1999); la ayuda ofrecida por los padres (Madjar, Shklar \& Moshe, 2016; Núñez, Suárez, Rosário, Vallejo, Valle, et al., 2015); o el feedback dado por el profesor (Núñez, Suárez, Rosário, Vallejo, Cerezo, et al., 2015).

\subsubsection{Motivación hacia los deberes escolares}

La motivación está considerada como una parte esencial en el proceso de los deberes escolares y, a su vez, la realización de dichos deberes requiere que los estudiantes tengan la voluntad de participar en ellos y persistir. En este sentido, existen indicios de que gran parte del alumnado se implica en los deberes no por el interés o entusiasmo que le producen, sino por otras razones como pueden ser el deseo de agradar, de cumplir con sus obligaciones o incluso por evitar castigos (Regueiro, Suárez, Valle, Núñez y Rosário, 2015).

De este modo, tal y como sugiere la investigación llevada a cabo por Ryan y Deci (2000), la magnitud y el tipo de motivación que los escolares desarrollan y mantienen se 
vincula directamente con el grado y la calidad de su implicación. Asimismo, los motivos que tenga el alumno para hacer los deberes, su grado de interés y la utilidad que perciba inciden en el grado de implicación hacia la tarea (cantidad de deberes realizados, tiempo dedicado y aprovechamiento de este) y en consecuencia en su rendimiento académico (Pan et al., 2013). Así, la motivación intrínseca y la utilidad percibida de los deberes se encuentran significativa y positivamente asociados con el compromiso del estudiante con los mismos, y este compromiso se relaciona también positivamente con el rendimiento académico (Rodríguez et al., 2020).

Por otro lado, cuando los estudiantes se inician en la escuela sienten una gran emoción por la idea de hacer los deberes, sin embargo, al cabo de un breve periodo de tiempo ese interés y entusiasmo se va perdiendo y decrece de modo significativo (Coutts, 2004). Este hecho concuerda con algunos estudios, como el realizado por Regueiro et al. (2015) en el que se pone de manifiesto que tanto el tipo de motivación hacia los deberes como su intensidad cambian a medida que los escolares avanzan de curso académico.

\subsubsection{Enfoques de trabajo al hacer los deberes escolares}

En el proceso de realización de las tareas para casa el papel del alumno es determinante, pues es el agente que decide si las va a realizar, cómo lo va a hacer y que estrategias va a poner en marcha para resolverlas. Así, cuando un estudiante se enfrenta a los deberes debe decidir sobre cómo enfocar su trabajo y gestionar sus recursos, tanto personales, como ambientales.

Todo parece indicar que el tipo de estrategia o el enfoque de trabajo empleado al hacer los deberes está relacionado, no sólo con la ejecución final de esas tareas, sino también con la calidad del proceso de realización de las mismas. En este sentido, se pueden identificar dos grandes enfoques de trabajo: el enfoque superficial y el enfoque profundo. Los estudiantes que adoptan un enfoque superficial ponen en marcha estrategias para aprender la información de manera mecánica y repetitiva. Asimismo, el alumno va a realizar los deberes porque se siente obligado por el docente o sus padres, siendo su principal objetivo terminar lo antes posible para dedicarse a otras actividades más lúdicas. Por otro lado, el uso de un enfoque profundo al hacer los deberes implica una intención por aprender y reforzar los contenidos adquiridos en clase, mostrando un interés intrínseco en la materia que está cursando. De esta manera, tratará de resolver las dudas que se le planteen y utilizará estrategias que le permitan alcanzar una comprensión significativa de los contenidos, tratando de relacionarlos con sus conocimientos previos.

Los resultados de varios estudios evidencian que, cuando las estrategias utilizadas son propias de un aprendizaje profundo, el aprovechamiento es mayor que cuando los deberes son realizados de modo superficial. Por lo tanto, es más importante el cómo se realizan los deberes que "el cuánto", es decir, la cantidad de tareas desarrolladas (Fernández-Alonso, Suárez-Álvarez y Muñiz, 2014). Por otra parte, siguiendo a Núñez, Vallejo, Rosário, Tuero y Valle (2014), cuanto más utilice un alumno el enfoque profundo de estudio, mayor será su rendimiento académico y, cuanto más superficial sea el enfoque que utilice, menor será su rendimiento. En definitiva, la utilización de un enfoque profundo por parte del estudiante va a suponer que sostenga una motivación intrínseca y un mayor uso de estrategias de autorregulación en el aprendizaje. 


\subsection{VARIABLES CONTEXTUALES IMPLICADAS EN LOS DEBERES ESCOLARES}

\subsubsection{Feedback del profesorado ante los deberes escolares}

La gran mayoría del profesorado asigna deberes a sus alumnos. Principalmente lo hacen porque consideran que hacer las tareas para casa contribuye a mejorar el rendimiento académico, a incrementar la motivación, la capacidad de autorregulación de los estudiantes y que ayuda a establecer una relación positiva entre la escuela y la familia (Cooper et al., 1998; Epstein y Van Voorhis, 2001).

Asimismo, uno de los objetivos del profesorado es que el alumnado realice los deberes escolares para consolidar los contenidos y aprendizajes iniciados en el aula. Sin embargo, para alcanzar este propósito, las tareas para casa deben estar ajustadas y adaptadas, tanto al propio estudiante, como al tema, pues sólo así se podrá favorecer a los alumnos con bajas capacidades e incrementar su interés por completarlas (Epstein y Van Voorhis, 2001). Del mismo modo, resulta clave su actuación el día posterior a la prescripción de los deberes, ya que el efecto que estas tareas provocan sobre el rendimiento es mayor cuando el docente analiza y comenta los resultados en el aula. De igual forma, hacer explícita la importancia y la utilidad de realizar las tareas para casa supone un incentivo en la motivación intrínseca del estudiante (Murillo y Martínez-Garrido, 2013). En cualquier caso, para que el feedback resulte eficaz debe aportar información sobre el progreso alcanzado por el alumno, así como, pautas de actuación futura que contribuyan a su mejora.

Por otro lado, el feedback proporcionado por los profesores no es igual en todos los niveles de escolaridad. Siguiendo la investigación realizada por Katz, Kaplan y Gueta (2010), los alumnos de octavo grado perciben menos apoyo por parte de los profesores en relación con los deberes que sus compañeros de cuarto grado, apoyo que ha demostrado afectar significativamente a la motivación de los alumnos hacia los deberes escolares. Por lo tanto, a medida que se asciende de curso desciende progresivamente la percepción por parte de los estudiantes de feedback de los profesores ante los deberes.

\subsubsection{Implicación parental en los deberes escolares}

No menos importante resulta ser el feedback proporcionado por los padres y madres de los estudiantes, pues los deberes constituyen una actividad que se realiza fuera de la escuela y, en ausencia del profesorado, los supervisores deben ser los padres (Suárez, Regueiro, Tuero, Cerezo y Rodríguez, 2014).

Sin duda, las tareas para casa son la actividad por excelencia que relaciona a los padres con los hijos, además de una de las formas más comunes de implicación parental. En este sentido, la implicación parental hace referencia a la interacción de los padres con sus hijos y el centro educativo, con el fin de promover el éxito académico. Siguiendo a Epstein y Van Voorhis (2001) los padres pueden tener diferentes intenciones y utilizar diferentes estrategias de acción, pero generalmente la mayoría considera que ayudar a los hijos con sus deberes es su responsabilidad. Estos mismos autores sostienen, además, que el apoyo de los progenitores constituye un factor esencial para la implicación de sus hijos en los deberes, por lo que ofrecer un apoyo afectivo y emocional puede contribuir a mejorar la motivación y el interés hacia los deberes escolares, así como el rendimiento académico. 


\section{EDUCACIÓN Y DIVERSIDAD CULTURAL}

Aunque el sistema educativo es considerado un agente compensador de las desigualdades, todavía existen diferencias generacionales, regionales e incluso de género que tienen un gran impacto en el fracaso y abandono escolar. En este contexto, la falta de interés y la baja implicación familiar en las cuestiones educativas es considerada como una de las causas de ese fracaso o abandono escolar, siendo necesarias actuaciones que consigan paliar el avance de esta situación. Uno de los fenómenos que puede motivar dichas diferencias radica en el porcentaje actual de población extranjera en nuestro país, siendo esta una realidad que ha influido de forma relativamente rápida y desigual en los centros educativos. Además, la presencia de estudiantes extranjeros impacta en la estructura del sistema educativo por lo que resulta necesario implementar una serie de adecuaciones en respuesta a las necesidades y contingencias advertidas (Valdés, Jiménez, HernándezYáñez y Fardell, 2020).

Así pues, se considera población extranjera residente en España aquella que no posee la nacionalidad española. Siguiendo el Informe sobre el estado del sistema educativo (MECD, 2019) y centrando la atención en los menores de 16 años (edad límite de la educación obligatoria), 733.883 jóvenes con nacionalidad extranjera eran residentes en España en el año 2018 y de ellos el 36,5 \% tenían edades comprendidas entre los 6 y los 11 años y el 20,6 \% entre los 12 y 15 años, lo que se corresponde con las etapas de Educación Primaria y Secundaria respectivamente. Atendiendo a la distribución por Comunidades Autónomas, la población extranjera se reparte de un modo no homogéneo siendo Cataluña es la que más población recoge. Con relación a la procedencia geográfica el 24\% de los menores de 16 años tienen sus raíces en Marruecos, seguido de Rumanía, China y Ecuador. Por otro lado, el nivel económico y social de las familias es otro de los factores que incide en el rendimiento académico del alumnado. Asimismo, las características de la población extranjera en cuanto a su cultura y tradición influyen de manera diferente en los resultados académicos y en la adaptación a la escuela.

En el marco de la Comunidad Autónoma de Galicia la llegada de población extranjera ha tomado gran relevancia, dejando de ser un referente de la emigración para pasar a convertirse en receptor de individuos procedentes de otros países (Santos y Lorenzo, 2009). Así, pues, siguiendo a estos autores, su trascendencia se relaciona con la heterogeneidad de los colectivos, procedentes de distintas nacionalidades y con diversos orígenes socioeducativos y económicos. No cabe duda de que la diversidad étnicocultural se ha incrementado en las últimas décadas. Los padres y madres extranjeros tienen claro que la escolarización de sus hijos es un factor clave de estabilidad, integración y promoción social. En este contexto se multiplica la importancia y la labor de la educación, bien sea por las condiciones previamente señaladas (religión, lengua, cultura, situación económica...) o porque a través del alumno, su núcleo familiar entrará en contacto con la cultura del país, favoreciendo así una adecuada inclusión (Fiuza y Fernández, 2013).

Así, pues, hoy en día se acepta que las aulas son multiculturales, pues en un mismo espacio confluyen diversas culturas. El objetivo último es llegar a alcanzar la interculturalidad, es decir, la interacción entre dos o más culturas de manera horizontal, sin supeditar una a la otra. De este modo, se podrá favorecer una adecuada integración y convivencia, suponiendo el respeto y la atención a la diversidad. Pero para ello se necesita 
de la implicación de todos los profesionales de la educación, los cuales deben disponer de estrategias y técnicas que permitan satisfacer las necesidades y lograr el éxito académico del alumnado, y en este contexto tienen cabida la prescripción de los deberes escolares.

Por otro lado, pertenecer a una minoría étnica o cultural puede traer consigo problemas interpersonales. El tutor constituye una figura esencial para superar cualquier limitación que los estereotipos culturales y sociales puedan imponer y, en este sentido, puede hablarse de desigualdades en el rendimiento académico o en el nivel de éxito escolar. En consecuencia, los alumnos que se desmarcan del resto del grupo-clase pierden toda motivación por el aprendizaje y confianza en su propia capacidad, lo que les impide invertir el esfuerzo necesario para realizar las tareas escolares, entre las que se incluyen los controvertidos deberes. De este modo, la limitación inicial se incrementa progresivamente, por lo que se debe proporcionar a todo el alumnado un nivel de reconocimiento adecuado (Fiuza y Fernández, 2013). Con relación a la intervención con la familia, estas mismas autoras consideran fundamental que los centros educativos lleven a cabo actuaciones que permitan su implicación directa, con el fin de asegurar el apoyo de los padres en las tareas escolares, reducir posibles sentimientos de infravaloración y contribuir a favorecer la valoración de la familia hacia la escuela.

En definitiva, el acceso a la educación es una de las principales vías de inclusión y promoción social, por lo que proporcionar una educación de calidad a los alumnos extranjeros debe ser una prioridad. Sin embargo, el carácter socializador de la escuela es limitado, por lo que sería conveniente ampliar las actividades complementarias y extraescolares, estimular la participación de los niños y adolescentes extranjeros en los centros de ocio y entornos educativos no formales, así como establecer mecanismos que favorezcan una adecuada relación con la familia.

Los escasos estudios realizados con población extranjera sobre los deberes escolares (Bang, 2011; Mau y Lynn, 1999) aportan datos muy generales en los que esta relación se explora grosso modo, por lo que resulta necesario abordar específicamente la relación entre la implicación del alumno en los deberes y el rendimiento académico (Suárez et al., 2016). Además, no son objeto de análisis variables tan importantes como la cantidad de deberes que hacen el alumnado de los prescritos, el tiempo invertido en realizar deberes, el aprovechamiento del tiempo a la hora de hacer deberes, o la calidad de los deberes realizados y su relación con el rendimiento académico.

\section{OBJETIVOS DEL TRABAJO}

Partiendo de esta realidad, el propósito de este trabajo se centra en analizar si estas variables contenidas en el modelo de Trautwein y Köller (2003), relativas a la implicación del alumno en los deberes y a la influencia del contexto, siguen las mismas pautas o no en todo el alumnado. De manera más concreta, se plantea la cuestión de si el alumnado extranjero manifiesta en el proceso de realización de los deberes escolares dificultades que puedan marcar diferencias con el alumnado no extranjero. Por tanto, el interés de esta investigación se centra más en analizar las variables implicadas en el proceso de realización de de los deberes escolares y no tanto en estudiar la relación entre deberes y rendimiento académico. No obstante, si el proceso de realización es el adecuado, los deberes repercutirán positivamente en el rendimiento académico. 
En síntesis, el principal objetivo de este trabajo es comprobar si hay diferencias en ciertas variables relacionadas con los deberes escolares entre estudiantes extranjeros y no extranjeros y analizar, además, si esas diferencias varían en función de la etapa educativa (Primaria y Secundaria).

\section{MÉTODO}

\subsection{PARTICIPANTES}

En el estudio participaron 94 estudiantes pertenecientes a seis centros públicos de Galicia (España). El 43.6\% ( $\mathrm{N}=41)$ son chicos y el 56.4\% ( $\mathrm{N}=91)$ son chicas. De edades comprendidas entre los 9 y los 16 años, el $49 \%(\mathrm{~N}=46)$ cursaban los tres últimos cursos de Educación Primaria y el 51\% ( $=48)$ cursaban Educación Secundaria Obligatoria (ESO). Del total de la muestra, el $44.7 \%(\mathrm{~N}=42)$ eran alumnos extranjeros y el $55.3 \%(\mathrm{~N}$ $=52$ ) eran no extranjeros. La distribución de alumnos extranjeros y no extranjeros en cada curso es muy similar. La selección de los participantes se realizó tratando de que hubiera una proporción similar en el número de alumnos extranjeros y no extranjeros en cada uno de los cursos.

\subsection{INSTRUMENTOS DE MEDIDA}

Para evaluar los enfoques de trabajo al realizar los deberes se utilizó el Inventario de Procesos de Estudio (IPE), elaborado por Rosário, Núñez y González-Pienda (2006). El cuestionario está compuesto por 12 ítems agrupados en dos factores o dimensiones: enfoque superficial y enfoque profundo. Este instrumento está basado en algunos trabajos sobre los enfoques de aprendizaje y estudio (Biggs, Kember y Leung, 2001; Rosário et al., 2005) y aporta información sobre dos enfoques de trabajo al hacer los deberes escolares: enfoque superficial $(\mathrm{a}=.67)$ (ej., ítem: "suelo hacer los deberes, pero pocas veces me fijo en cómo lo estoy haciendo") y enfoque profundo $(\mathrm{a}=.87)$ (ej., ítem: "antes de ponerme a hacer los deberes suelo pensar si tengo claro lo que se ha dado en clase y, si no es así, repaso la lección antes de comenzar"). Los ítems son presentados en un formato tipo likert con cinco alternativas de respuesta que van desde 1 (totalmente falso) hasta 5 (totalmente cierto).

Para medir el resto de las variables relacionadas con los deberes escolares se utilizó la Encuesta sobre los Deberes Escolares (EDE), que es una escala que evalúa diferentes dimensiones relativas a la eficacia de los deberes para el aprendizaje y rendimiento académico de los alumnos. De hecho, numerosos estudios han utilizado estas dimensiones para evaluar diversas variables relacionadas con los deberes escolares (Núñez, Suárez, Cerezo et al., 2015; Núñez, Suárez, Rosário, Vallejo, Valle et al., 2015; Valle, Pan, Núñez et al., 2015; Valle, Pan, Regueiro et al., 2015; Valle et al., 2016). En concreto, las dimensiones evaluadas son las siguientes:

- La estimación de la cantidad de deberes realizados por los alumnos se obtuvo mediante las respuestas a un ítem relativo a la cantidad de deberes realizados habitualmente, utilizando para ello una escala tipo likert con cinco alternativas (1 = ninguno, 2 = algunos, 3 = la mitad, $4=$ casi todos, $5=$ todos $)$. 
- En cuanto al tiempo diario dedicado a la realización de los deberes, los estudiantes respondieron a tres ítems (en general, en una semana típica, en un fin de semana típico) con la formulación general “¿Cuánto tiempo sueles dedicar a la realización de los deberes?", siendo las opciones de respuesta $1=$ menos de 30 minutos, $2=$ de 30 minutos a una hora, $3=$ de una hora a hora y media, $4=$ de hora y media a dos horas, $5=$ más de dos horas $(\mathrm{a}=.70)$.

- El aprovechamiento del tiempo dedicado a los deberes se evaluó a través de las respuestas a tres ítems (en general, en una semana típica, en un fin de semana típico) en los que se les pedía que indicaran el nivel de aprovechamiento del tiempo dedicado habitualmente a los deberes, utilizando para ello la siguiente escala: $1=$ lo desaprovecho totalmente (me distraigo constantemente con cualquier cosa), $2=$ lo desaprovecho más de lo que debiera, $3=$ regular, $4=$ lo aprovecho bastante, $5=$ lo aprovecho totalmente (me concentro y hasta terminar no pienso en otra cosa) (a $=.75)$.

- La motivación intrínseca hacia los deberes escolares se evaluó mediante ocho ítems $(\mathrm{a}=.84)$, referidos a razones vinculados con el disfrute, satisfacción y el aprendizaje en la realización de los deberes escolares. La escala de respuesta va desde " 1 = totalmente falso" a " $5=$ totalmente cierto".

- La ansiedad ante los deberes se evaluó mediante cuatro ítems (p. e., "solo pensar en hacer los deberes me pone nervioso"), con una escala tipo likert con cinco alternativas que van desde " $1=$ totalmente falso" a " $5=$ totalmente cierto" $(\mathrm{a}=$ $.81)$.

- La percepción del feedback del profesorado se evaluó a través de nueve ítems en los que se mide el grado de implicación y supervisión que hacen los profesores de los deberes escolares de sus alumnos $(\mathrm{a}=.76)$.

- La percepción de los estudiantes de la implicación parental en los deberes escolares se evaluó mediante ocho ítems que se agrupan en dos dimensiones diferentes: percepción de apoyo parental $(\mathrm{a}=78)$, que está formada por tres ítems referidos al grado de apoyo afectivo y emocional por parte de los padres cuando sus hijos están haciendo los deberes; y percepción de control parental $(\mathrm{a}=.78)$, que está integrada por cinco ítems referidos al grado de control que ejercen los padres respecto a la realización de los deberes por parte de sus hijos. La escala de respuesta va desde " 1 = totalmente falso" a " 5 = totalmente cierto".

\subsection{PROCEDIMIENTO}

Los datos referidos a las variables objeto de estudio fueron recogidos durante el horario escolar, previo consentimiento del equipo directivo y de los profesores de los alumnos.

\subsection{ANÁLISIS DE DATOS}

Con la finalidad de dar respuesta a los objetivos del trabajo, se realizó un análisis multivariado de varianza (MANOVA) tomando como factores el grupo de procedencia de los estudiantes (con dos niveles: extranjero y no extranjero) y la etapa educativa (con dos niveles: Primaria y Secundaria), y como variables dependientes la cantidad de deberes realizados (de los prescritos por el profesorado), el tiempo dedicado a los deberes, el aprovechamiento del 
tiempo dedicado a los deberes, la motivación intrínseca hacia los deberes, la ansiedad ante los deberes, el enfoque de trabajo profundo, el enfoque de trabajo superficial, la percepción del feedback del profesorado ante los deberes, la percepción de control parental al hacer los deberes y la percepción de apoyo parental al hacer los deberes.

Como medida del tamaño del efecto se utilizó el coeficiente eta-cuadrado parcial $\left(\eta_{\mathrm{p}}{ }^{2}\right)$, ya que es uno de los procedimientos usados habitualmente dentro de la investigación educativa (ver, p.e., Sun, Pan y Wang, 2010). Para la interpretación de los tamaños del efecto se utiliza el criterio establecido en el trabajo clásico de Cohen (1988), en base al cual un efecto es pequeño cuando $\eta_{\mathrm{p}}{ }^{2}=.01(d=.20)$, el efecto es medio cuando $\eta_{\mathrm{p}}{ }^{2}=.059$ $(d=.50)$ y el tamaño del efecto es grande si $\eta_{\mathrm{p}}^{2}=.138(d=.80)$.

\section{RESULTADOS}

Los resultados del MANOVA indican que hay diferencias estadísticamente significativas en el conjunto de variables relacionadas con los deberes escolares en función del grupo de procedencia (no extranjeros y extranjeros) (Lambda de Wilks $=.669, F(10,74)=3.66$, $\left.p<.001, \eta_{\mathrm{p}}{ }^{2}=.331\right)$ y de la etapa educativa (Primaria y Secundaria) (Lambda de Wilks = $\left..622, F(10,74)=4.49, p<.001, \eta_{\mathrm{p}}{ }^{2}=.378\right)$. En ambos casos, el tamaño del efecto es grande.

En cuanto a los resultados referidos a cada variable dependiente contemplada individualmente, hay diferencias estadísticamente significativas, en función del grupo de estudiantes (no extranjeros y extranjeros), en la cantidad de deberes realizados $(F(1,83)$ $\left.=7.54, p<.01, \eta_{\mathrm{p}}{ }^{2}=.083\right)$ y en la percepción del control parental al realizar los deberes $\left(F(1,83)=11.20, p<.001, \eta_{\mathrm{p}}{ }^{2}=.119\right)$. En ambos casos, el tamaño del efecto es medio.

Estos resultados indican que el grupo de estudiantes no extranjeros realiza una cantidad de deberes (de los prescritos por el profesorado) significativamente mayor que el grupo de estudiantes extranjeros (ver tabla 1). Por otro lado, el grupo de estudiantes extranjeros percibe un control parental al hacer los deberes significativamente mayor que el que percibe el grupo de estudiantes no extranjeros (ver tabla 2).

Por lo que se refiere a las diferencias en cada una de las variables dependientes en función de la etapa educativa (Primaria y Secundaria), los resultados indican que hay diferencias estadísticamente significativas en la cantidad de deberes realizados $(F(1,83)=$ $\left.7.61, p<.01, \eta_{\mathrm{p}}{ }^{2}=.084\right)$, en el aprovechamiento del tiempo dedicado a los deberes $(F(1,83)$ $\left.=9.43, p<.01, \eta_{\mathrm{p}}{ }^{2}=.102\right)$, en la motivación intrínseca hacia los deberes $(F(1,83)=15.56$, $\left.p<.001, \eta_{\mathrm{p}}{ }^{2}=.158\right)$, en el enfoque de trabajo profundo al hacer los deberes $(F(1,83)=15.62$, $\left.p<.001, \eta_{\mathrm{p}}{ }^{2}=.158\right)$, en la percepción de feedback del profesorado ante los deberes $(F(1,83)$ $\left.=13.34, p<.001, \eta_{\mathrm{p}}{ }^{2}=.138\right) \mathrm{y}$ en la percepción del control parental al hacer los deberes $\left(F(1,83)=9.44, p<.01, \eta_{\mathrm{p}}{ }^{2}=.102\right)$. Los tamaños del efecto son grandes en el caso de la motivación intrínseca, del enfoque de trabajo profundo y de la percepción de feedback del profesorado, y medios en las otras variables.

Según estos resultados, los estudiantes de Primaria realizan una mayor cantidad de deberes (de los prescritos por el profesorado), aprovechan más el tiempo dedicado a esos deberes, están más motivados intrínsecamente, utilizan más un enfoque de trabajo profundo al hacer los deberes, perciben un mayor feedback por parte de sus profesores y perciben un mayor control parental cuando hacen los deberes que los estudiantes de Secundaria (ver tabla 1 y tabla 2). 
Tabla 1. Estadísticos descriptivos (media, desviación típica) correspondientes a la implicación, motivación y ansiedad ante los deberes escolares en función del grupo de estudiantes (no extranjeros y extranjeros) y de la etapa educativa (Primaria y Secundaria)

\begin{tabular}{|c|c|c|c|c|c|c|}
\hline & \multicolumn{2}{|c|}{ No extranjeros } & \multicolumn{2}{|c|}{ Extranjeros } & \multicolumn{2}{|c|}{ Total } \\
\hline & M & DT & M & DT & M & DT \\
\hline \multicolumn{7}{|c|}{ Cantidad de deberes realizados } \\
\hline \multirow{3}{*}{$\begin{array}{l}\text { Primaria } \\
\text { Secundaria } \\
\text { Total }\end{array}$} & 4.71 & 0.53 & 4.06 & 1.26 & 4.46 & 0.94 \\
\hline & 4.05 & 1.08 & 3.55 & 1.06 & 3.78 & 1.08 \\
\hline & 4.45 & 0.85 & 3.78 & 1.16 & 4.14 & 1.06 \\
\hline \multicolumn{7}{|c|}{ Tiempo dedicado a los deberes } \\
\hline \multirow{2}{*}{$\begin{array}{l}\text { Primaria } \\
\text { Secundaria }\end{array}$} & 2.21 & 0.92 & 2.50 & 1.04 & 2.33 & 0.97 \\
\hline & 3.00 & 1.11 & 2.50 & 1.10 & 2.73 & 1.12 \\
\hline Total & 2.53 & 1.06 & 2.50 & 1.06 & 2.52 & 1.05 \\
\hline \multicolumn{7}{|c|}{ Aprovech. tiempo deberes } \\
\hline \multirow{2}{*}{$\begin{array}{l}\text { Primaria } \\
\text { Secundaria }\end{array}$} & 3.82 & 0.90 & 3.44 & 1.34 & 3.67 & 1.10 \\
\hline & 2.89 & 1.15 & 2.95 & 0.90 & 2.93 & 1.01 \\
\hline Total & 3.45 & 1.10 & 3.18 & 1.13 & 3.32 & 1.11 \\
\hline \multicolumn{7}{|c|}{ Motivación intrínseca deberes } \\
\hline \multirow{3}{*}{$\begin{array}{l}\text { Primaria } \\
\text { Secundaria } \\
\text { Total }\end{array}$} & 4.12 & 0.70 & 4.10 & 0.96 & 4.11 & 0.80 \\
\hline & 3.45 & 0.82 & 3.45 & 0.60 & 3.45 & 0.70 \\
\hline & 3.84 & 0.81 & 3.74 & 0.83 & 3.80 & 0.82 \\
\hline \multicolumn{7}{|c|}{ Ansiedad ante los deberes } \\
\hline \multirow{2}{*}{$\begin{array}{l}\text { Primaria } \\
\text { Secundaria }\end{array}$} & 1.76 & 1.10 & 1.90 & 0.75 & 1.81 & 0.97 \\
\hline & 1.42 & 0.71 & 1.84 & 0.89 & 1.64 & 0.83 \\
\hline Total & 1.62 & 0.96 & 1.86 & 0.82 & 1.73 & 0.90 \\
\hline
\end{tabular}


Tabla 2. Estadísticos descriptivos (media, desviación típica) correspondientes a los enfoques de trabajo, percepción del feedback del profesorado y percepción del control parental al hacer los deberes en función del grupo de estudiantes (no extranjeros y extranjeros) y de la etapa educativa (Primaria y Secundaria)

\begin{tabular}{|c|c|c|c|c|c|c|}
\hline & \multicolumn{2}{|c|}{ No extranjeros } & \multicolumn{2}{|c|}{ Extranjeros } & \multicolumn{2}{|c|}{ Total } \\
\hline & M & DT & M & DT & M & DT \\
\hline \multicolumn{7}{|c|}{ Enfoque de trabajo profundo } \\
\hline \multirow{3}{*}{$\begin{array}{l}\text { Primaria } \\
\text { Secundaria } \\
\text { Total }\end{array}$} & 3.72 & 1.06 & 3.92 & 1.05 & 3.80 & 1.05 \\
\hline & 2.98 & 0.80 & 2.99 & 0.90 & 2.99 & 0.84 \\
\hline & 3.42 & 1.02 & 3.41 & 1.06 & 3.41 & 1.03 \\
\hline \multicolumn{7}{|c|}{ Enfoque de trabajo superficial } \\
\hline \multirow{2}{*}{$\begin{array}{l}\text { Primaria } \\
\text { Secundaria }\end{array}$} & 2.63 & 0.97 & 3.24 & 0.82 & 2.87 & 0.95 \\
\hline & 3.21 & 0.80 & 3.14 & 0.57 & 3.17 & 0.68 \\
\hline Total & 2.86 & 0.94 & 3.19 & 0.69 & 3.01 & 0.85 \\
\hline \multicolumn{7}{|c|}{ Percep. feedback profesorado } \\
\hline \multirow{2}{*}{$\begin{array}{l}\text { Primaria } \\
\text { Secundaria }\end{array}$} & 4.10 & 0.55 & 3.81 & 0.84 & 3.98 & 0.69 \\
\hline & 3.25 & 0.63 & 3.54 & 0.79 & 3.41 & 0.73 \\
\hline Total & 3.76 & 0.71 & 3.66 & 0.81 & 3.71 & 0.76 \\
\hline \multicolumn{7}{|c|}{ Percep. control parental } \\
\hline \multirow{3}{*}{$\begin{array}{l}\text { Primaria } \\
\text { Secundaria } \\
\text { Total }\end{array}$} & 3.38 & 0.99 & 3.91 & 1.00 & 3.59 & 1.02 \\
\hline & 2.56 & 0.99 & 3.44 & 0.89 & 3.03 & 1.03 \\
\hline & 3.05 & 1.06 & 3.65 & 0.96 & 3.32 & 1.05 \\
\hline \multicolumn{7}{|c|}{ Percepción apoyo parental } \\
\hline \multirow{2}{*}{$\begin{array}{l}\text { Primaria } \\
\text { Secundaria }\end{array}$} & 3.87 & 1.25 & 3.37 & 1.24 & 3.67 & 1.26 \\
\hline & 2.79 & 1.37 & 3.44 & 1.22 & 3.14 & 1.32 \\
\hline Total & 3.43 & 1.40 & 3.41 & 1.21 & 3.42 & 1.31 \\
\hline
\end{tabular}

Aunque no se han encontrado diferencias estadísticamente significativas en el resto de las variables, sí se observa una cierta tendencia en los resultados que vamos a comentar a continuación. Así, el grupo de estudiantes no extranjeros realiza mayor cantidad de deberes que el grupo de extranjeros, pero en ambos grupos la cantidad de deberes realizados es menor en Secundaria que en Primaria (ver figura 1). 
Con respecto al tiempo dedicado a los deberes, el grupo de extranjeros dedica el mismo tiempo a hacer los deberes en Primaria y en Secundaria. En cambio, el grupo de no extranjeros dedica más tiempo a hacer los deberes en Secundaria (ver figura 2).

El aprovechamiento del tiempo es ligeramente superior en el grupo de no extranjeros en Primaria, pero disminuye en ambos grupos en Secundaria (esa disminución es mayor en el grupo de no extranjeros) (ver figura 3 ).

Figura 1. Valores medios en cantidad de deberes realizados obtenidos por los estudiantes extranjeros y no extranjeros en Primaria y Secundaria.

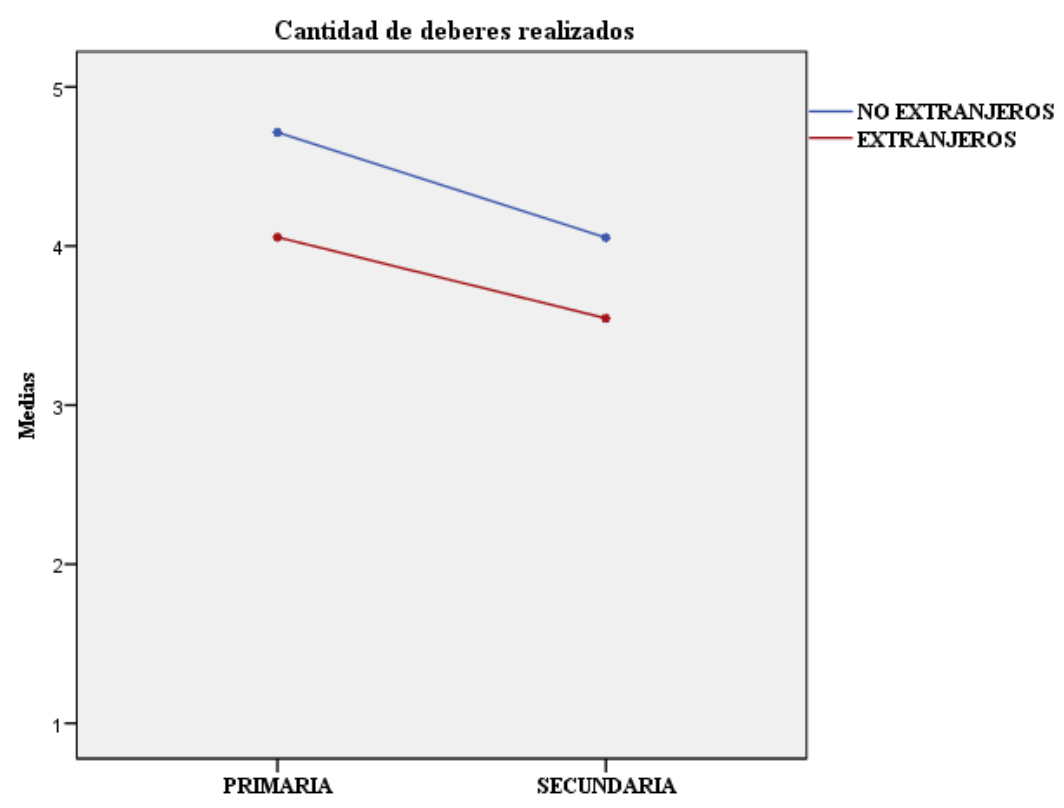


Figura 2. Valores medios en tiempo dedicado a los deberes obtenidos por los estudiantes extranjeros y no extranjeros en Primaria y Secundaria.

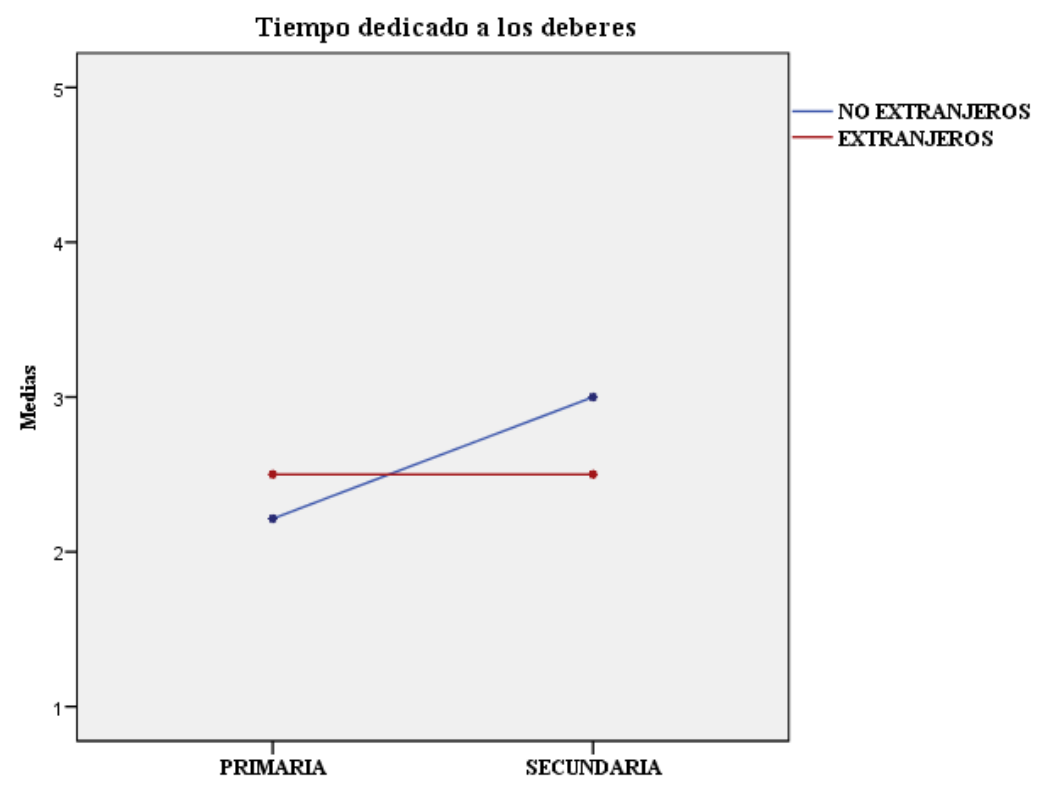

Figura 3. Valores medios en aprovechamiento del tiempo dedicado a los deberes obtenidos por los estudiantes extranjeros y no extranjeros en Primaria y Secundaria.

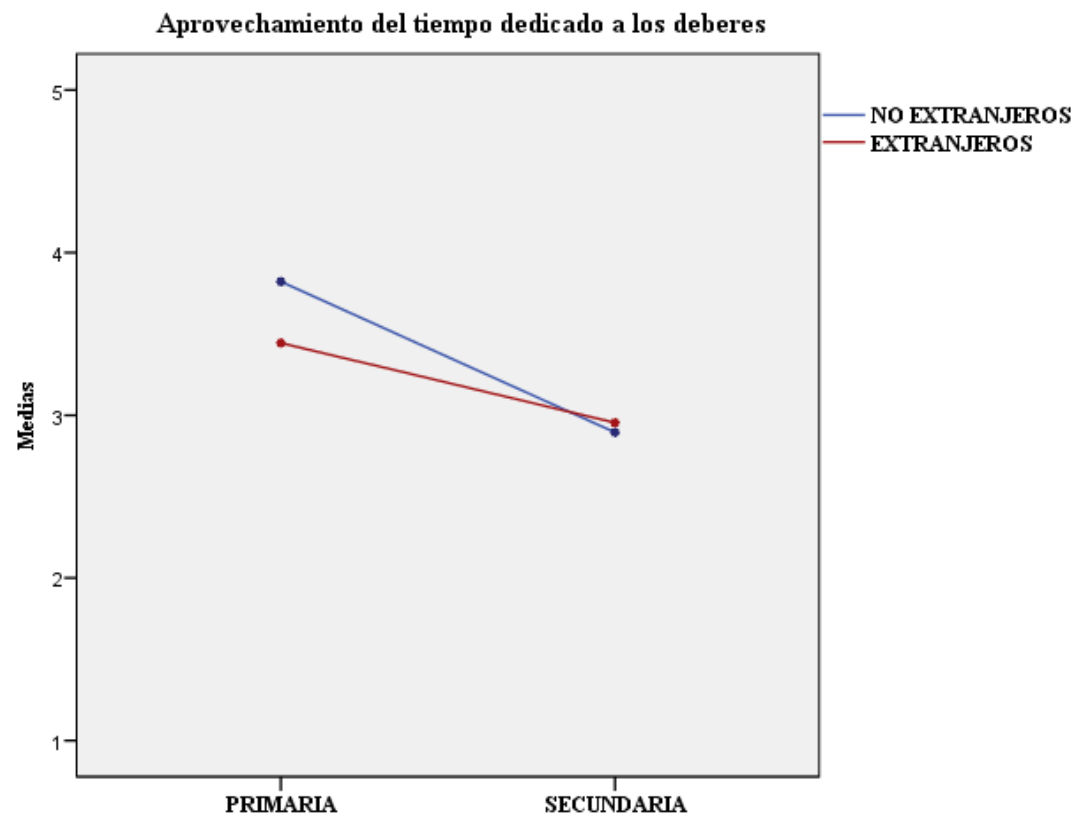


Por otro lado, la motivación intrínseca hacia los deberes es más baja en ambos grupos (no extranjeros y extranjeros) en Secundaria que en Primaria (ver figura 4).

La ansiedad ante los deberes es más bien baja en ambos grupos (no extranjeros y extranjeros) y en ambas etapas educativas, aunque hay una mayor disminución en Secundaria en el caso del grupo de estudiantes no extranjeros (ver figura 5).

El enfoque de trabajo profundo al hacer los deberes es más bajo en ambos grupos (no extranjeros y extranjeros) en Secundaria que en Primaria (ver figura 6).

El enfoque de trabajo superficial al hacer los deberes es más alto en el grupo de estudiantes extranjeros en Primaria, pero en Secundaria aumenta en el caso del grupo de estudiantes no extranjeros, llegando a ser muy similares en ambos grupos (ver figura 7).

Figura 4. Valores medios en motivación intrínseca hacia los deberes obtenidos por los estudiantes extranjeros y no extranjeros en Primaria y Secundaria.

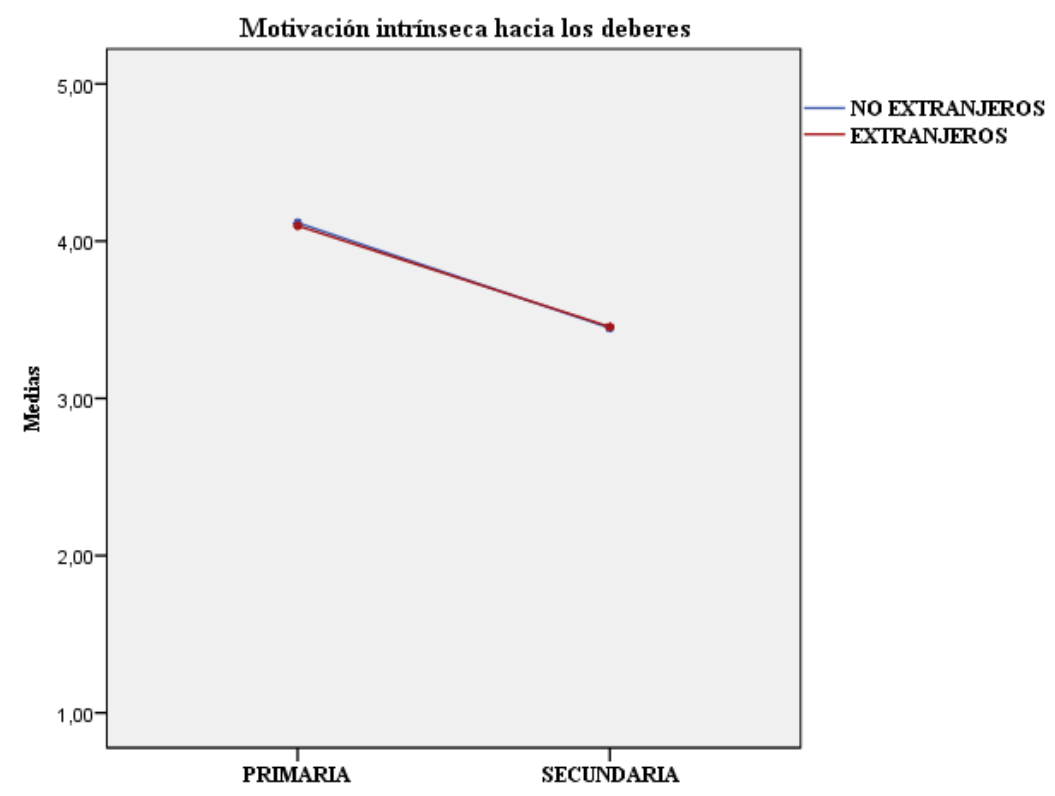


Figura 5. Valores medios en ansiedad ante los deberes obtenidos por los estudiantes extranjeros y no extranjeros en Primaria y Secundaria.

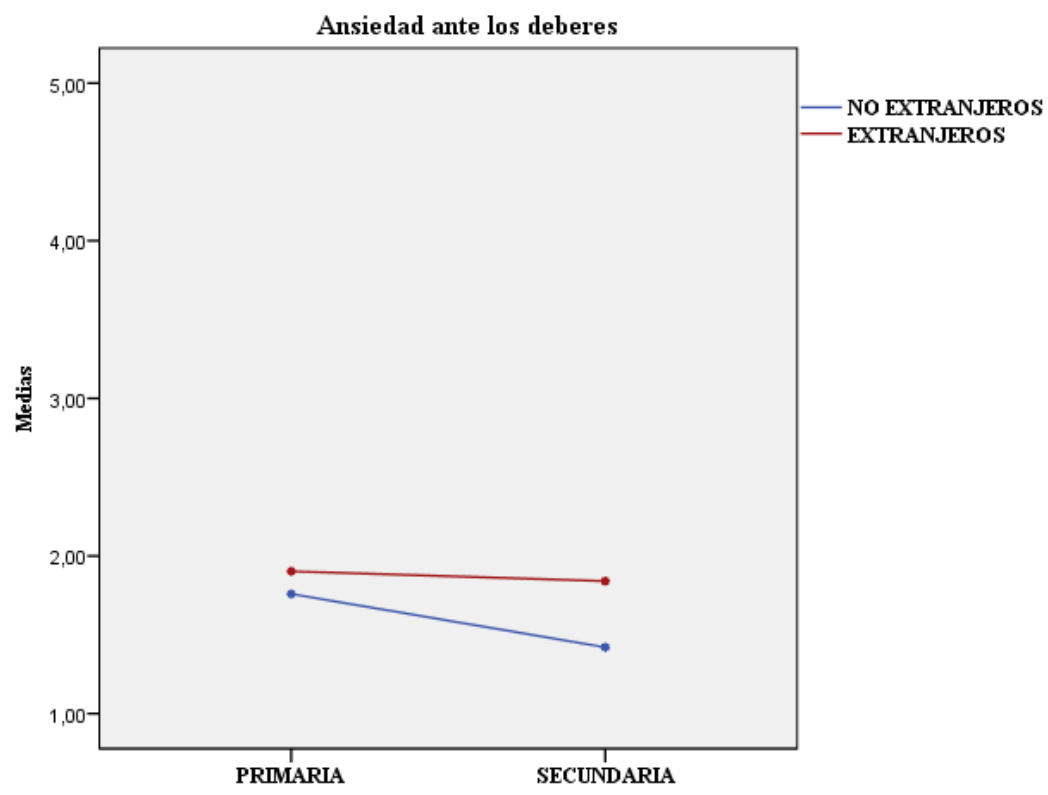

Figura 6. Valores medios en enfoque de trabajo profundo obtenidos por los estudiantes extranjeros y no extranjeros en Primaria y Secundaria.

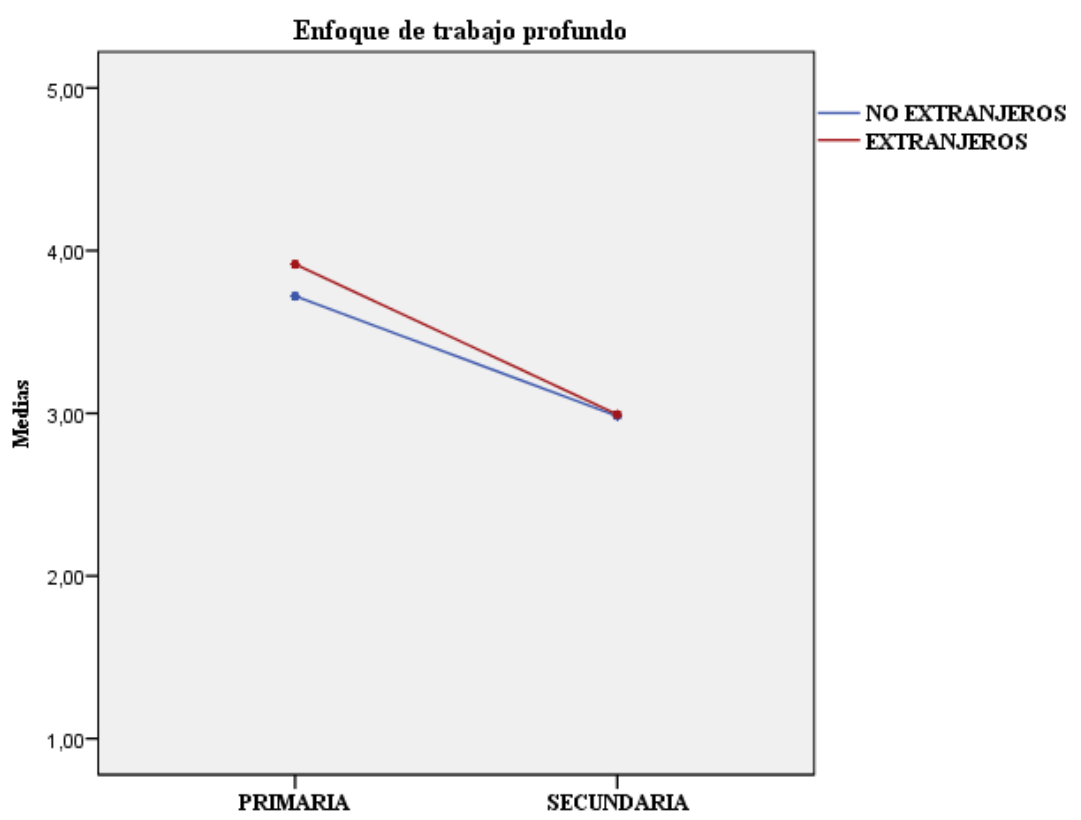


Figura 7. Valores medios en enfoque de trabajo superficial obtenidos por los estudiantes extranjeros y no extranjeros en Primaria y Secundaria.

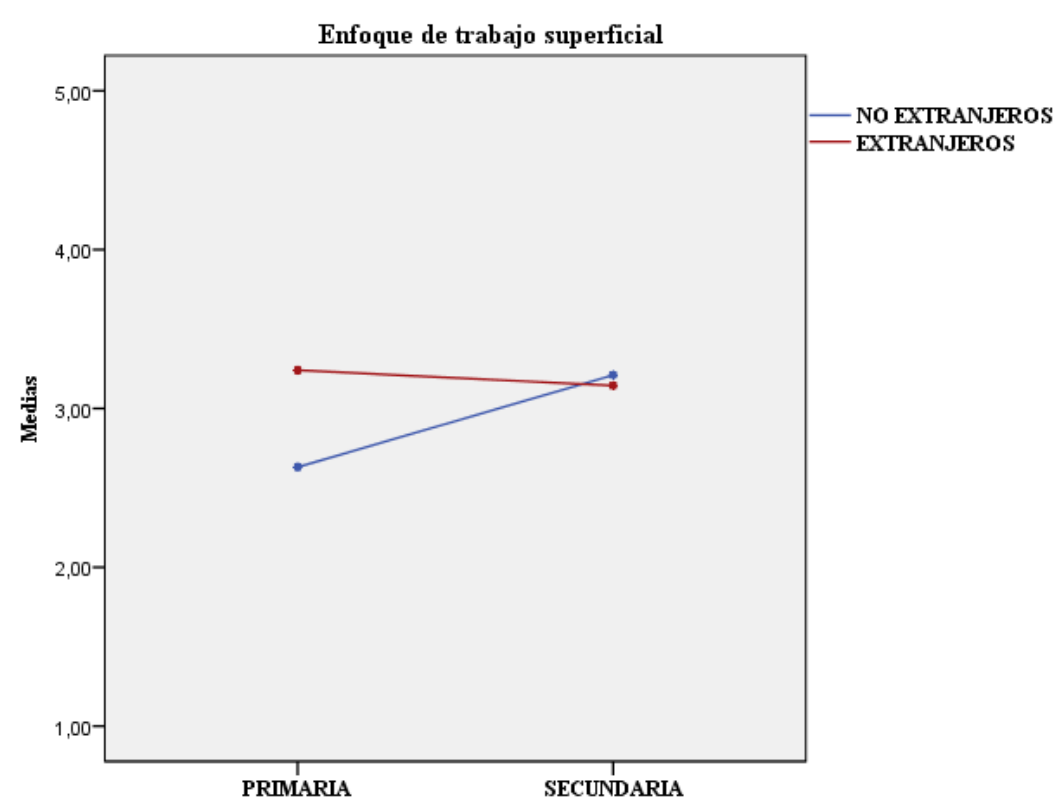

La percepción del feedback de profesorado ante los deberes es ligeramente superior en el grupo de no extranjeros en Primaria, pero en Secundaria es un poco mayor en el grupo de extranjeros (ver figura 8).

La percepción del control parental al hacer los deberes es mayor en el grupo de extranjeros, pero en ambos grupos esa percepción disminuye desde Primaria a Secundaria (ver figura 9).

La percepción del apoyo parental al hacer los deberes es ligeramente superior en el grupo de no extranjeros en Primaria, pero en Secundaria es un poco mayor en el grupo de extranjeros (ver figura 10). 
Figura 8. Valores medios en percepción del feedbak del profesorado ante los deberes obtenidos por los estudiantes extranjeros y no extranjeros en Primaria y Secundaria.

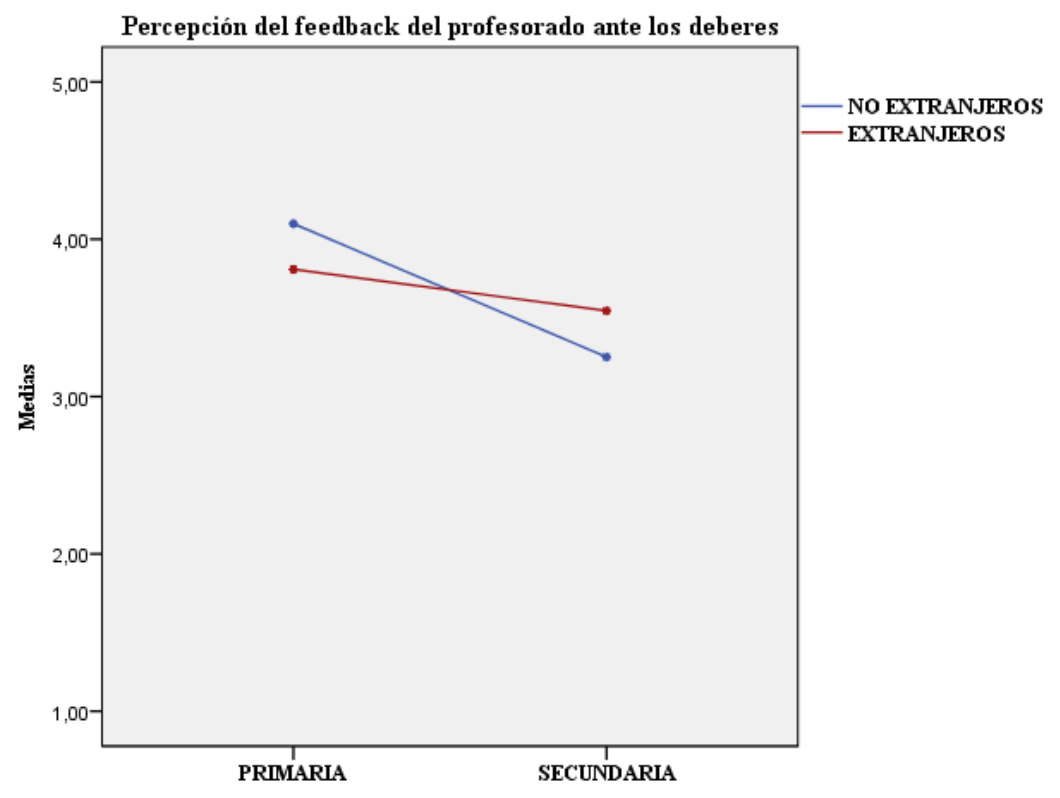

Figura 9. Valores medios en percepción del control parental ante los deberes obtenidos por los estudiantes extranjeros y no extranjeros en Primaria y Secundaria.

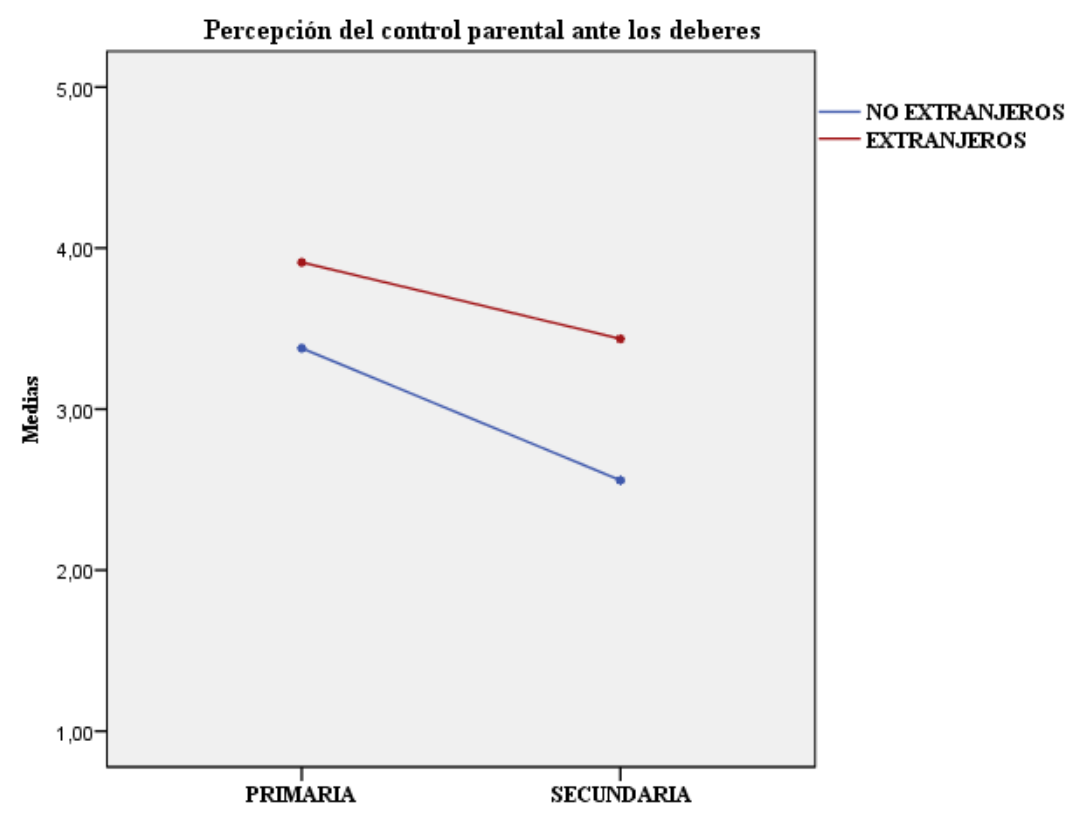


Figura 10. Valores medios en percepción del apoyo parental ante los deberes obtenidos por los estudiantes extranjeros y no extranjeros en Primaria y Secundaria.

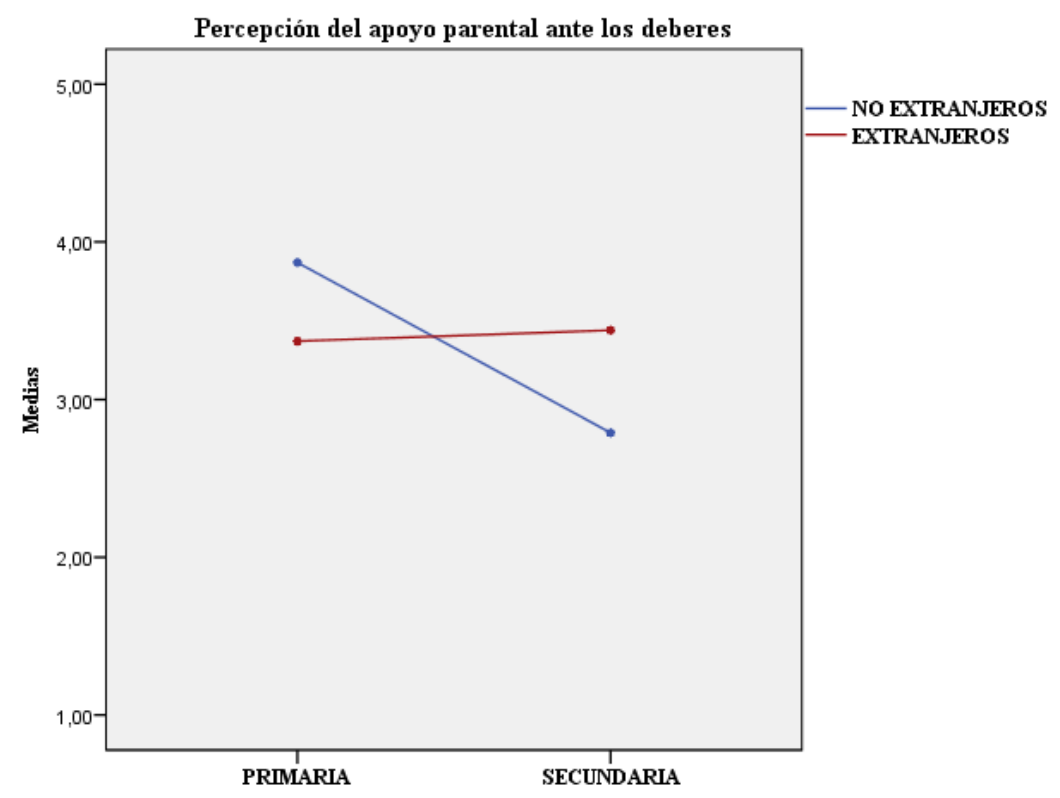

\section{DISCUSIÓN Y CONCLUSIONES}

Los resultados ponen de manifiesto que el grupo de estudiantes no extranjeros realiza una cantidad de deberes, de los prescritos por el profesorado, mayor que el grupo de estudiantes extranjeros. No obstante, en ambos grupos la cantidad de deberes realizados es menor en Secundaria que en Primaria. Estos resultados coinciden con los obtenidos por Suárez et al. (2016), donde a medida que se suceden los cursos disminuye la cantidad de deberes realizados de los prescritos. Éstos también concuerdan con la literatura previa en alumnado nativo (Núñez et al., 2015).

Por lo tanto, si el grupo de estudiantes no extranjeros realiza una mayor cantidad de deberes, su rendimiento académico se espera que sea mayor que el del grupo de extranjeros. No obstante, en la etapa de Secundaria la cantidad de deberes realizada por ambos grupos desciende, aunque el grupo de no extranjeros continúa realizando más cantidad de deberes que los extranjeros.

Con relación al tiempo dedicado a los deberes, los resultados no evidencian diferencias en el tiempo que dedica el grupo de extranjeros en Primaria y Secundaria. Sin embargo, el grupo de estudiantes no extranjeros dedica más tiempo a hacer los deberes en Secundaria. Tal y como se comentó en la introducción de este trabajo, la literatura existente ha mostrado discrepancias respecto a la relación entre el tiempo dedicado a los deberes y el rendimiento académico. Así, mientras para Keith (1982) un incremento en el tiempo empleado por los alumnos, especialmente en los cursos más elevados, tiene un efecto positivo, otros autores como Trautwein (2007) encuentran esta relación débil e incluso negativa. 
Los datos de un estudio realizado por Núñez et al. (2014) en el que se analizaron datos de estudiantes de los dos últimos cursos de Primaria y del primer y segundo ciclo de Secundaria, mostraron como la relación entre el tiempo dedicado a los deberes y el rendimiento académico difiere según la etapa educativa en la que se encuentren los alumnos. Así, pues, la edad no sólo es una variable importante en esta relación, sino que la condiciona notablemente. De igual modo, los resultados del mencionado trabajo evidenciaron además que la cantidad de tiempo dedicado a los deberes es ligeramente mayor con el paso de los cursos. Esto concuerda con los resultados obtenidos en el presente estudio con relación al grupo de no extranjeros, donde la tendencia indica que en la etapa de Secundaria el tiempo dedicado a los deberes es mayor que en Primaria.

Por otro lado, los estudiantes no extranjeros en Primaria hacen un aprovechamiento del tiempo superior a los extranjeros. En la etapa de Secundaria este aprovechamiento del tiempo disminuye en ambos grupos, siendo este descenso más acentuado en el grupo de extranjeros.

La literatura científica se ha ocupado de estudiar la relación entre la cantidad de deberes realizados, el tiempo dedicado a los mismos y el rendimiento académico. Sin embargo, los mejores resultados académicos se asocian con un mejor aprovechamiento del tiempo. Asimismo, los datos obtenidos en la investigación de Suárez (2015) indican que la relación entre el aprovechamiento del tiempo y el rendimiento académico es más fuerte cuanta mayor edad tienen los estudiantes. Sin embargo, también se observa que el aprovechamiento del tiempo dedicado a los deberes decrece a medida que los alumnos asisten a cursos superiores. Estos datos concuerdan con la presente investigación, en la que se pone de manifiesto que cuanta mayor edad tienen los estudiantes, menor es el aprovechamiento del tiempo dedicado a los deberes, y esto ocurre, tanto con el alumnado extranjero, como no extranjero. En la investigación llevada a cabo con muestra extranjera por Suárez et al. (2016) también se han encontrado diferencias en ambos grupos, pero existe discrepancia en la dirección en función de la fuente que informe: mientras que los estudiantes no extranjeros manifiestan que se concentran más que los extranjeros en la realización de los deberes escolares, los padres de los estudiantes no extranjeros indican que sus hijos desaprovechan más el tiempo de lo que indican los padres de los niños extranjeros.

Con respecto a la motivación intrínseca del estudiante hacia los deberes, los resultados no evidencian diferencias entre el alumnado extranjero y no extranjero, pues ambos grupos tienden a estar menos motivados a medida que avanzan de curso académico. Así, la motivación intrínseca tanto en el grupo de extranjeros como de no extranjeros es más baja en la etapa de Secundaria que en Primaria. Esto concuerda con la investigación llevada a cabo por Coutts (2004) en la que se demuestra que, cuando los estudiantes se inician en la escuela, sienten una gran emoción por la idea de realizar las tareas para casa, pero a medida que pasa el tiempo ese interés y entusiasmo decrece y se va perdiendo. De igual modo, los resultados obtenidos en esta investigación coinciden con el estudio llevado a cabo por Regueiro et al. (2015) en el que se muestra que, tanto el tipo de motivación hacia los deberes, como su intensidad cambian a medida que los estudiantes avanzan de curso académico, estableciéndose diferencias entre la etapa de Primaria y la de Secundaria.

En este sentido cabe considerar también la ansiedad ante los deberes, la cual se mantiene baja en ambos grupos (extranjeros y no extranjeros) en las dos etapas (Educación 
Primaria y Educación Secundaria). Asimismo, la tendencia indica una mayor disminución en Secundaria en el caso del grupo de estudiantes no extranjeros. Las puntuaciones bajas en esta variable reflejan que el proceso de realización de los deberes escolares no provoca niveles elevados de ansiedad en los estudiantes que participaron en esta investigación. Estos resultados se consideran positivos desde el punto de vista educativo y no coinciden con los aportados por autores como Galloway et al. (2013), quienes defienden que prescribir deberes a los escolares incrementa el riesgo de sufrir problemas de salud psicológica, tales como estrés o ansiedad, repercutiendo, no solo en el alumnado, sino también en padres y profesores.

Con relación a los enfoques de trabajo, los resultados manifiestan que el uso de un enfoque profundo al hacer los deberes es menor en Secundaria que en Primaria, tanto en los estudiantes extranjeros como no extranjeros. Por su parte, el enfoque superficial al hacer los deberes es mayor en el grupo de estudiantes extranjeros en Primaria, pero en Secundaria aumenta en el caso del grupo de estudiantes no extranjeros, llegando a ser muy similares en ambos grupos. Estos resultados coinciden con otras investigaciones que demuestran que el tipo de enfoque que utilizan los estudiantes para afrontar los deberes tiende a ser más superficial que profundo a medida que van avanzando de curso. Así, en el trabajo de Regueiro et al. (2015) se encuentra que, a medida que el alumnado avanza en edad, asocia el estudio y la realización de los deberes escolares con tareas poco significativas y motivantes. Si el alumnado no encuentra útiles las tareas para casa va a utilizar un enfoque más superficial, siendo su única pretensión aprobar las asignaturas sin detenerse a analizar lo que está aprendiendo; es decir, sin utilizar estrategias que impliquen reflexión, interpretación y razonamiento. De este hecho puede deducirse, tal y como se evidenció en la presente investigación, que el aprovechamiento del tiempo a la hora de realizar los deberes disminuye a medida que se asciende de curso académico, pues no se sienten motivados intrínsecamente por la tarea a realizar.

Por otro lado, en cuanto al feedback del profesorado ante los deberes los resultados muestran que éste es percibido es mayor medida por los alumnos no extranjeros en Primaria. No obstante, en la etapa de Secundaria es el grupo de estudiantes extranjeros el que lo percibe en mayor grado. En cualquier caso, la tendencia indica que tanto el grupo de estudiantes no extranjeros como extranjeros perciben un menor feedback del profesorado en la etapa de Secundaria que en Primaria. Estos resultados concuerdan con la investigación llevada a cabo por Katz et al. (2010) en la que se observa que el feedback proporcionado por los profesores respecto a los deberes no es igual en todos los niveles de escolaridad, pues los alumnos de octavo grado perciben un menor apoyo por parte de sus docentes que los alumnos de cuarto grado. Este apoyo afecta significativamente a la motivación de los alumnos hacia los deberes, coincidiendo con los resultados obtenidos en la presente investigación con relación a esta variable, la cual tiende a bajar a medida que se avanza de curso escolar.

En cuanto al feedback proporcionado por los padres puede decirse, por un lado, que los estudiantes extranjeros perciben un mayor control parental, aunque en ambos grupos esta percepción disminuye desde Primaria a Secundaria. Por otro lado, el grupo de no extranjeros en Primaria percibe un mayor apoyo parental al hacer los deberes, aspecto que en Secundaria es mayor en el grupo de estudiantes extranjeros.

Estos resultados guardan una estrecha relación con los obtenidos en el estudio de Suárez (2015) en el que, de manera general, se ratifica que la implicación parental en el 
contexto de la realización de los deberes escolares desciende a medida que el alumnado asciende de curso escolar, al igual que ocurre con la implicación del profesor. De manera más concreta, en dicho estudio se evidencia que el efecto de la implicación parental sobre el aprovechamiento del tiempo al hacer los deberes es significativo en la etapa de Secundaria. Esto concuerda con los resultados de la presente investigación respecto a esta última variable en ambos grupos (extranjeros y no extranjeros), pues desciende de Primaria a Secundaria, al igual que tiende a hacerlo el control y apoyo parental percibido por los estudiantes ante los deberes.

Como cualquier otro trabajo de estas características, este estudio posee ciertas limitaciones que se hace necesario mencionar. Así pues, el tamaño total de la muestra y el número de participantes en cada curso, sobre todo extranjeros, debería ser más numeroso para cumplir adecuadamente los criterios de representatividad y poder ofrecer mayores garantías a la hora de generalizar los resultados. Por otra parte, la información obtenida procede de cuestionarios que fueron cubiertos por los propios alumnos, por lo que dicha información podría variar si procediese de los padres o de los profesores del alumnado. De igual modo, el número de ítems empleados para medir ciertas variables influyentes en el proceso de realización de los deberes escolares podría ser mayor con el fin de obtener resultados más precisos. Por último, otra de las limitaciones se encuentra en que este estudio se centró únicamente en el nivel del alumno sin reflejar el nivel de la clase o del centro educativo y en este sentido, tal y como plantean Trautwein y Köller (2003), los resultados obtenidos podrían ser diferentes.

No obstante, a pesar de las limitaciones indicadas, esta investigación pretende tener transcendencia a nivel educativo. Uno de sus principales propósitos ha sido servir como motor para abrir nuevas líneas de investigación que contribuyan a seguir avanzando en torno a esta temática, pues los estudios que tratan las diferencias entre el alumnado extranjero y no extranjero con relación a los deberes escolares son escasos.

No cabe duda de que la educación es un pilar fundamental en la sociedad y para darle la consideración que merece se necesita investigar y conocer la realidad educativa, promoviendo en consonancia cambios que vayan desde el campo de la investigación hasta la práctica educativa en el aula. Los responsables de la educación deben ser conscientes del papel que cumplen las diferentes variables que influyen en el proceso de realización de los deberes escolares, pues sólo así el alumnado podrá alcanzar el éxito académico independientemente de razones culturales o de procedencia que puedan suponer motivo de desigualdad.

Así pues, el debate sobre si es conveniente o no prescribir deberes a los escolares y en qué medida hacerlo es algo que está presente en nuestra sociedad. Los argumentos que apoyan ambas posturas son numerosos, pero sin embargo en este debate existen cuestiones más interesantes, como es el hecho de reflexionar acerca de si estas tareas son de calidad y si se ajustan a las necesidades particulares de los estudiantes, incluyendo la procedencia del alumnado; si sirven para implicar más al alumno en el proceso de aprendizaje; o si contribuyen a vincular a las familias con la escuela, teniendo en cuenta todo tipo de factores, incluidos los multiculturales.

Tal y como se expuso en el presente trabajo, las variables que influyen en el proceso de realización de los deberes escolares son amplias y complejas, siendo necesario abordarlas con más detalle para poder obtener resultados más eficaces que contribuyan a mejorar la calidad y equidad de la educación. 


\section{REFERENCIAS BIBLIOGRÁFICAS}

Bang, H. J. (2011). Newcomer immigrant students' perspectives on what affects their homework experiences. The Journal of Educational Research, 104(6), 408-419. doi: 10.1080/00220671.2010.499139

Biggs, J., Kember, D. \& Leung, D. Y. (2001). The revised Two Factor Study Process Questionnaire: R-SPQ-2F. British Journal Educational Psychology, 71,133-149. doi:10.1348/000709901158433

Cohen, J. (1988). Statistical power analysis for the behavioral sciences (2nd Ed.). Hillsdale, NJ: Erlbaum.

Cooper, H., Lindsay, J. J., Nye, B. \& Greathhouse, S. (1998). Relationships among attitudes about homework, amount of homework assigned and completed, and student achievement. Journal of Educational Psychology, 90(1), 70-83. doi:10.1037/0022-0663.90.1.70

Cooper, H., Robinson, J. \& Patall, E. (2006). Does homework improve academic achievement? A synthesis of research, 1987-2003. Review of Educational Research, 76(1), 1-62. doi: $10.3102 / 00346543076001001$

Coutts, P. M. (2004). Meanings of homework and implications for practice. Theory into Practice, 43(3), 182-188.

Epstein, J. L. \& Van Voorhis, F. L. (2001). More than minutes. Teacher's roles in designing homework. Educational Psychologist, 36(3), 181-193. doi:10.1207/s15326985ep3603_4

Fan, H., Xu, J., Cai, Z., He, J. \& Fan, X. (2017). Homework and students' achievement in math and science: a 30-year meta-analysis, 1986-2015. Educational Research and Reviews, 20, 35-54.

Fernández-Alonso, R., Suárez-Álvarez, J. \& Muñiz, J. (2014). Tareas escolares en el hogar y rendimiento en Matemáticas: una aproximación multinivel con estudiantes de Enseñanza Primaria. Revista de Psicología y Educación, 9(2), 15-29.

Fernández-Alonso, R., Álvarez-Díaz, M., Suárez-Álvarez, J. \& Muñiz, J. (2017). Students' Achievement and Homework Assignment Strategies. Frontiers in Psychology, 8, 286. doi: 10.3389/fpsyg.2017.00286

Fiuza, M. J. \& Fernández, M. P. (2013). Dificultades de aprendizaje y trastornos del desarrollo. Manual didáctico. Madrid: Pirámide.

Galloway, M., Conner, J. \& Pope, D. (2013). Nonacademic effects of homework in privileged, highperforming high schools. The Journal of Experimental Education, 81(4), 490-510. doi:10.1080 /00220973.2012.745469

Katz, I., Kaplan, A. \& Gueta, G. (2010). Students' needs, teachers' support and motivation for doing homework: A cross-sectional study. Journal of Experimental Education, 78(2), 246-267. doi:10.1080/00220970903292868

Keith, T. Z. (1982). Time spent on homework and High School Grades: A large-sample path analysis. Journal of Educational Psychology, 74(2), 248-253.

MECD (2019). Informe 2015 sobre el estado del sistema educativo. Curso 2017-2018. Recuperado el 11 de septiembre de 2020 desde http://www.educacionyfp.gob.es/dam/jcr:4f35ae94-f996-4cebb3f0-21b2e421ec26/i19cee-informe.pdf

Madjar, N., Shklar, N. \& Moshe, L. (2016). The role of parental attitudes in children's motivation toward homework assignments. Psychology in the Schools, 53(2), 173-188. doi: 10.1002/pits.21890

Mau, W. \& Lynn, R. (1999). Racial and ethnic differences in motivation for educational achievement in the United States. Personality and Individual Differences, 27(6), 1091- 1096.

Murillo, F. J. \& Martínez-Garrido, C. (2013). Incidencia de las tareas para casa en el rendimiento académico. Un estudio con estudiantes iberoamericanos de Educación Primaria. Revista de Psicodidáctica, 18(1), 157-178.

Núñez, J. C., Suárez, N., Cerezo, R., González-Pienda, J. A., Rosário, P., Mourão, R. \& Valle, A. (2015). Homework and academic achievement across Spanish Compulsory Education. Educational Psychology, 35(6), 726-746. doi:10.1080/01443410.2013.817537 
Núñez, J. C., Suárez, N., Rosário, P., Vallejo, G., Cerezo, R. \& Valle, A. (2015). Teachers’ feedback on homework, homework-related behaviors and academic achievement. Journal of Educational Research, 108(3), 204-216. doi:10.1080/00220671.2013.878298

Núñez, J. C., Suárez, N., Rosário, P., Vallejo, G., Valle, A. \& Epstein, J. L. (2015). Relationships between parental involvement in homework, student homework behaviors, and academic achievement: Differences among elementary, junior high, and high school students. Metacognition and Learning. 10, 375-406. doi:10.1007/s11409-015- 9135-5

Núñez, J. C., Vallejo, G., Rosário, P., Tuero, E. \& Valle, A. (2014). Variables del estudiante, del profesor y del contexto en la predicción del rendimiento académico en Biología: análisis desde una perspectiva multinivel. Revista de Psicodidáctica, 19(1), 145-172.

Pan, I., Regueiro, B., Ponte, B., Rodríguez, S., Piñeiro, I. \& Valle, A. (2013). Motivación, implicación en los deberes escolares y rendimiento académico. Aula Abierta, 41(3), 13-22. doi:10.1016/j. aula.2016.03.001

Regueiro, B., Pan, I., Sánchez, B., Valle, A., Núñez, J. C. \& Rosário, P. (2014). Diferencias en la implicación en los deberes escolares en función del rendimiento académico en estudiantes de Primaria. International Journal of Developmental and Educational Psychology, 1(7), 437-448. doi:10.17060/ijodaep.2014.n1.v7.813

Regueiro, B., Suárez, N., Estévez, I., Rodríguez, S., Piñeiro, I. \& Valle, A. (2018). Deberes escolares y rendimiento académico: un estudio comparativo entre el alumnado inmigrante y nativo. Journal of Psychology and Education, 13(2), 92-98, doi: 10.23923/rpye2018.01.160

Regueiro, B., Suárez, N., Valle, A., Núñez, J. C. \& Rosário, P. (2015). La motivación e implicación en los deberes escolares a lo largo de la escolaridad obligatoria. Revista de Psicodidáctica, 20(1), 47-63. doi:10.1387/revpsicodidact.12641

Rodríguez, S., Piñeiro, I., Regueiro, B. \& Estévez, I. (2020). Intrinsic motivation and perceived utility as predictors of student homework engagement. Revista de Psicodidáctica, 25(2), 93-99. doi: 10.1016/j.psicoe.2019.11.001

Rosário, P., Núñez, J. C. \& González-Pienda, J. A. (2006). Comprometer-se com o estudar na Universidade: "Cartas do Gervásio ao seu Umbigo». Coimbra: Almedina.

Rosário, P., Núñez, J. C., González-Pienda, J. A., Almeida, L., Soares, S. \& Rúbio, M. (2005). El aprendizaje escolar examinado desde la perspectiva del Modelo 3P de J. Biggs. Psicothema, 17(1), 20-30.

Ryan, E. M. \& Deci, E.L. (2000). Self-determination theory and the facilitation of intrinsic motivation, social development, and well-being. American Psychologist, 55(1), 68-78. doi:10.1037//0003066x.55.1.68

Santos, M. A. \& Lorenzo, M. M. (2009). La participación de las familias inmigrantes en la escuela. Un estudio centrado en la procedencia. Revista de Educación, 350, 277-300.

Suárez, N., Regueiro, B., Epstein, J. L., Piñeiro, I., Díaz, S. M. \& Valle, A. (2016). Homework involvement and academic achievement of native and immigrant students. Frontiers in Psychology, section Educational Psychology, 7, 1517. doi: 10.3389/fpsyg.2016.01517

Suárez, N., Regueiro, B., Tuero, E., Cerezo, R. \& Rodríguez, C. (2014). La implicación familiar en el ámbito educativo como herramienta para trabajar el éxito académico. Revista de Psicología y Educación, 9(2), 83-93.

Suárez. N. (2015). Deberes escolares y rendimiento académico en estudiantes de educación obligatoria (Tesis doctoral). Universidad de Oviedo, Oviedo.

Sun, S., Pan, W. \& Wang, L.L. (2010). A comprehensive review of effect size reporting and interpreting practices in academic journals in education and psychology. Journal of Educational Psychology, 102(4), 989-1004. doi:10.1037/a0019507

Trautwein, U. (2007). The homework-achievement relation reconsidered: Differentiating homework time, homework frequency, and homework effort. Learning and Instruction, 17(3), 372-388. doi:10.1016/j.learninstruc.2007.02.009 
Trautwein, U. \& Köller, O. (2003). The relationship between homework and achievement-still much of a mystery. Educational Psychology Review, 15(2), 115-145. doi: 10.1023/A:1023460414243

Valdés, R., Jiménez, F., Hernández-Yáñez, M. \& Fardella, C. (2020). Dispositivos de acogida para estudiantes extranjeros como plataformas de intervención formativa. Estudios Pedagógicos, 45(3), 261-278. doi:10.4067/S0718-07052019000300261

Valle, A., Pan, I., Núñez, J. C., Rosário, P., Rodríguez, S. \& Regueiro, B. (2015). Deberes escolares y rendimiento académico en Educación Primaria. Anales de Psicología, 31(2), 562-569. doi:10.6018/analesps.31.2.171131

Valle, A., Pan, I., Regueiro, B., Suárez, N., Tuero. E. \& Nunes, A. R. (2015). Predicting approach to homework in Primary school students. Psicothema, 27(4), 334-340. doi: 10.7334/ psicothema2015.118

Valle, A., Piñeiro, I., Rodríguez, S., Regueiro, B., Freire, C. \& Rosário, P. (2019). Time spent and time management in homework in elementary school students: A person-centered approach. Psicothema, 31(4), 422-428. doi: 10.7334/psicothema2019.191

Valle, A., Regueiro, B., Núñez, J. C., Rodríguez, S., Piñeiro, I. \& Rosário, P. (2016). Academic goals, student homework engagement, and academic achievement in elementary school. Frontiers in Psychology, 7, 1-10. doi:10.3389/fpsyg.2016.00463 